\title{
Índices de crescimento de Brachiaria brizantha cv. Marandu adubadas com fontes e doses de silício ${ }^{1}$
}

Growth rates of Brachiaria brizantha cv. Marandu fertilized with sources of silicon

Kathery Brennecke

Isac Silveira Baptista Júnior ${ }^{3}$

Thiago Rossi Simões ${ }^{3}$

Thiago Albuquerque Tassim ${ }^{4}$

Gabriela Strozzi ${ }^{5}$

\section{Resumo}

O objetivo do experimento foi avaliar características morfométricas de Brachiaria brizantha cv. Marandu adubada com fontes de silício orgânico e inorgânico, e doses representativas a o, 100, 150, 200 e $250 \mathrm{~kg} \cdot \mathrm{ha}^{-1}$. O delineamento utilizado foi de parcelas subdivididas em um fatorial de $2 \mathrm{x}$ $5 \times 5$ (fontes de silício $x$ doses de silício $x$ repetições). Foram avaliados comprimento final de folhas e colmo, taxa de alongamento foliar e de colmo e intervalo de aparecimento foliar. O comprimento final das folhas foi significativo em função das fontes de silício utilizadas, porém observam-se diferenças $(p<0,01)$ a partir da quarta folha. A taxa de alongamento foliar, assim como o intervalo de aparecimento foliar e taxa de aparecimento foliar não apresentaram diferenças estatísticas significativas quando estudadas as fontes de silício nem quando estudadas as doses, o mesmo ocorrendo para o alongamento de colmo e o tamanho final de colmo. Concluise que tanto as fontes como as doses de silício não diferiram entre si e não influenciaram as medidas morfofisiológicas do capim-Marandu.

\section{Palavras-chave}

Braquiarão

Morfogênese

Silicato de cálcio

Silício orgânicol

\section{Abstract}

The objective of this experiment was to evaluate morphometric characteristics of Brachiaria brizantha cv. Marandu fertilized with sources of organic and inorganic silicon and levels representing $0,100,150,200$ and $250 \mathrm{~kg}$. ha ${ }^{-1}$. The experimental design was sub-divided plots in a factorial $2 \times 5 \times$ 5 (silicon's sources $x$ silicon's level $x$ repetitions). Were evaluated the final length of leaves and stem, leaf extension rate and stem and leaf appearance interval. The final leaf length was significant in terms of sources of silicon used, but differences were observed $(p<0,01)$ from the fourth leaf. In leaf elongation rate, as well as the range of leaf appearance and leaf appearance rate showed no statistically significant differences when studying the sources of silicon or when the doses studied, the same occurring for stem elongation and the final stem. We conclude that both sources of silicon doses did not differ among themselves and did not influence the measures of the morphophysiological Marandu grass. 


\section{1 | INTRODUC̣ÃO}

Para um bom manejo de pasto há a necessidade de se conhecer e compreender o processo de transformação e produção de folhas, e controlar os processos de crescimento e de desenvolvimento da forragem com a finalidade de ser consumida (NASCIMENTO JÚNIOR; ADESE, 2004). Segundo Gomide (1997), o entendimento da dinâmica de características morfogenéticas é o que permite a visualização da curva de produção do acúmulo de forragem e estimativa da qualidade do pasto.

O papel da morfogênese está diretamente ligado à expansão de órgãos vegetais no tempo e espaço, caracterizando em rendimento de massa seca da parte aérea (LEMAIRE; CHAPMAN, 1996). Nesse sentido, quando se entende a dinâmica de crescimento e desenvolvimento das plantas em uma pastagem e suas respostas morfofisiológicas, torna-se mais fácil adequar o manejo do pasto com produtividade e sustentabilidade. A morfogênese pode ser descrita por três características principais: taxa de aparecimento de folhas (TApF), taxa de alongamento de folhas (TAIF) e duração de vida da folha (DVF), onde a taxa de aparecimento de folhas exerce um papel fundamental devido a sua influência sobre os componentes da estrutura da pastagem, pois a contínua emissão de folhas e perfilhos é o que garante a produtividade e a perenidade da pastagem .

O silício tem sido considerado nutriente essencial para certas culturas, principalmente em gramíneas, nas quais os teores do elemento chegam a ser de dez a vinte vezes maiores que em dicotiledôneas (RAIJ, 1991), o que resulta em vários benefícios para as plantas, destacando-se maior tolerância da planta ao ataque de insetos (CARVALHO, 1998) e doenças (MENZIES et al., 2001), redução na transpiração (DATNOFF et al., 2001), maior taxa fotossintética das plantas, devido à melhoria na arquitetura foliar (DEREN, 2001).

Segundo Agarie et al. (1998), o aumento da capacidade fotossintética das plantas pode estar relacionado à presença do silício no sistema, por proporcionar melhor arranjo das foIhas, tornando-as, dessa maneira, mais eretas e mais resistentes a possíveis danos, além de reduzir a evapotranspiração das folhas meIhorando o aproveitamento de água. Epstein
(1994) comentou que o silício afeta positivamente o crescimento e produção de biomassa de um grande número de plantas (a maioria monocotiledôneas), por prover rigidez para suas estruturas.

Investigações sobre os mecanismos de silicio são largamente restritas às culturas como o arroz, trigo, cana de açúcar e pepino, mas muito pouco é conhecido sobre sua importância em vegetações naturais e pastagens artificiais e, segundo Sanches (2003), os mecanismos de ação do silício em plantas forrageiras ainda não são bem examinados. Diante disso torna-se importante um estudo visando índices de crescimento em Brachiaria brizantha cv. Marandu adubadas com fontes e doses de silício para identificar características morfológicas do Capim-Marandu e com isso poder compor dados que agreguem informações sobre o manejo e perenidade de forrageiras à literatura.

\section{2 | MATERIAL E MÉTODOS}

O experimento foi instalado em casa de vegetação na Universidade Camilo Castelo Branco, campus Descalvado, estado de São Paulo.

$O$ ensaio foi conduzido em vasos, em um esquema fatorial de $2 \times 5$, com cinco repetições. Foram consideradas duas fontes de silício (orgânica e inorgânica) e cinco doses: 0, 100, 150, 200 e $250 \mathrm{~kg} \cdot \mathrm{ha}^{-1}$. As fontes de silício orgânico e silicato de cálcio utilizadas possuíam, respectivamente, $5 \%$ e $22 \%$ de silício, e para aplicação foram efetuadas correções considerando o teor em porcentagem de cada produto.

A fonte silício inorgânico foi aplicada trinta dias antes da semeadura, devido a sua reação para solubilização no solo, porém a fonte de silício orgânico foi aplicada dois dias antes do plantio.

A semeadura foi feita diretamente nos vasos, utilizando dez sementes por vaso. Posteriormente, foram deixadas cinco plantas por vaso.

Para identificação das plantas a serem medidas, dois perfilhos, em cada vaso, foram marcados com arame colorido.

Após o aparecimento da segunda folha começaram as medidas de alongamento foliar e alongamento de colmo, a cada dois dias. Essas medidas foram realizadas com o auxilio de 
uma régua graduada em milímetros.

Posteriormente foram calculadas as respectivas taxas de alongamento foliar, alongamento do colmo, aparecimento foliar.

Foram analisados o tamanho final das foIhas completamente expandidas e o tamanho do colmo até a última medição. Os dados foram submetidos à análise de variância de regressão considerando $5 \%$ de probabilidade. A análise estatística foi realizada seguindo-se a metodologia do sistema estatístico SAS.

\section{3 | RESULTADO E DISCUSSÃO}

\section{Tamanho final das folhas e taxa de alongamento foliar}

O tamanho final da folha, observado na tabela 1, apresentou diferenças estatísticas significativas $(p<0,01)$ quando comparadas as fontes de silício utilizadas a partir da quarta folha $\left(\mathrm{F}_{4}\right)$, onde se pode observar um aumento em função do silício orgânico.

Altoé et al. (2008), trabalhando com caracterização morfológica de acessos de Brachiaria brizantha em casa de vegetação, obtiveram médias de tamanho final de folhas para o Marandu de $3,810,8 ; 9,720,16 ; 15,20,37$ para primeira, segunda e terceira folhas respectivamente. Segundo os mesmos autores, na quarta e quinta folha os cultivares de Brachiaria brizantha Xaraés obtiveram médias de $26 \pm 0,6$ e 33,4 40,5 $\mathrm{cm}$ respectivamente, e o cultivar $\mathrm{B} 166$ apresentou comprimento da quarta e quinta folha de

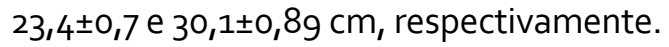

Tabela 1: Relação do tamanho $(\mathrm{cm})$ final das folhas em função dos tratamentos dentro de cada fonte

\begin{tabular}{lll}
\hline Tamanho final das folhas $(\mathrm{cm})$ & \\
\hline Folha & Silício Orgânico & Silicato de Cálcio \\
\hline 1 & $4,00 \mathrm{a}$ & $3,00 \mathrm{a}$ \\
2 & $8,00 \mathrm{a}$ & $7,00 \mathrm{a}$ \\
3 & $13,00 \mathrm{a}$ & $12,00 \mathrm{a}$ \\
4 & $21,00 \mathrm{a}$ & $19,00 \mathrm{~b}$ \\
5 & $31,00 \mathrm{a}$ & $27,00 \mathrm{~b}$ \\
6 & $44,00 \mathrm{a}$ & $39,00 \mathrm{~b}$ \\
\hline
\end{tabular}

Médias seguidas da mesma letra, na mesma linha, não diferem entre si ao nível de significância pelo teste Tukey. Fonte: Elaboração dos autores.

Observou-se também, que não houve diferenças significativas entre as doses utilizadas dentro de cada fonte de silício, conforme demonstrado na tabela 2. Apesar de não ter efei- to significativo, a utilização da fonte de silício orgânico apresentou folhas maiores, principalmente quando da utilização da dose representativa a $100 \mathrm{~kg} \cdot \mathrm{ha}^{-1}$.

Tabela 2. Relação entre as doses dentro de cada fonte de silício na taxa de alongamento foliar de cada folha (cm/dia)

\begin{tabular}{lll}
\hline \multicolumn{2}{l}{ Taxa de alongamento foliar (cm/dia) } & \\
\hline Tratamento & Silício Orgânico & Silicato de Cálcio \\
\hline 1 & $0,00 \mathrm{a}$ & $0,00 \mathrm{a}$ \\
2 & $0,00 \mathrm{a}$ & $0,00 \mathrm{a}$ \\
3 & $0,03 \mathrm{a}$ & $0,04 \mathrm{a}$ \\
4 & $0,07 \mathrm{a}$ & $0,07 \mathrm{a}$ \\
5 & $1,40 \mathrm{a}$ & $1,40 \mathrm{a}$ \\
6 & $2,90 \mathrm{a}$ & $3,10 \mathrm{a}$
\end{tabular}

Médias seguidas da mesma letra, na mesma linha, não diferem entre si ao nível de significância pelo teste Tukey. Fonte: Elaboração dos autores. 
$\mathrm{Na}$ aplicação com silicato de cálcio pôde-se observar que as folhas responderam gradativamente em função do aumento das doses aplicadas.

Em relação à taxa de alongamento foliar, observou-se que não houve diferenças estatísticas significativas entre as fontes de silício $(p>0,05)$ utilizadas assim como entre as doses $(p>0,05)$.

Tassim et al. (2009), trabalhando com défice hídrico em acessos de Brachiaria brizantha em casa de vegetação, obtiveram médias de 3,76 $\mathrm{cm} /$ dia de alongamento foliar dos tratamentos sem défice hídrico, com medidas a partir da quinta folha, o que difere do presente traba-
Iho, que teve o início das medidas a partir da primeira folha expandida. No presente trabaIho valores aproximados foram encontrados a partir da sexta folha.

\section{Intervalo de aparecimento foliar e taxa de aparecimento foliar}

Não foram observadas diferenças estatísticas significativas no intervalo de aparecimento foliar e na taxa de aparecimento foliar em função das doses e dos tratamentos com silício (tabelas 3 e 4 , respectivamente).

Tabela 3: Relação entre as doses de silício dentro de cada fonte no intervalo de aparecimento foliar em dias/folha/perfilho.

\begin{tabular}{lcl}
\hline Intervalo de Aparecimento Foliar (dias/folha/perfilho) & \\
\hline Tratamento & Silício Orgânico & Silicato de Cálcio \\
\hline 1 & $5,04 \mathrm{a}$ & $4,93 \mathrm{a}$ \\
2 & $4,94 \mathrm{a}$ & $5,01 \mathrm{a}$ \\
3 & $4,87 \mathrm{a}$ & $5,23 \mathrm{a}$ \\
4 & $5,28 \mathrm{a}$ & $5,04 \mathrm{a}$ \\
5 & $5,10 \mathrm{a}$ & $5,19 \mathrm{a}$ \\
\hline
\end{tabular}

Médias seguidas da mesma letra, na mesma linha, não diferem entre si ao nível de significância pelo teste Tukey. Fonte: Elaboração dos autores.

Trabalhando com caracterização morfogênica de cultivares de Brachiaria e Panicum em livre crescimento, Silveira (2006) obteve valores médios no intervalo de aparecimento foliar para o Marandu em torno de onze dias/folha. perfilho, e Alexandrino (2004), estudando características morfogênicas e estruturais na rebrotação da Brachiaria brizantha cv. Marandu submetida a três doses de nitrogênio, obteve resultados médios para o Marandu de 12,20 dias/folha.perfilho, o que difere dos resultados encontrados no presente experimento.
Em relação à taxa de aparecimento foliar, Dourado et al. (2009) encontraram valores de 0,0717 folha.perfilho-1 . $^{-1 a^{-1}}$ para parcelas adubadas com $483 \mathrm{~kg} / \mathrm{ha}^{-1}$ de nitrogênio e 0,0442 folha. perfilho ${ }^{-1}$. dia-1 e Silveira (2006) na caracterização morfogênica de cultivares de Brachiaria e Panicum em livre crescimento, obteve resultados médios para o Marandu de 0,09 folha.perfilho-1dia-1. Os autores não discriminam com quantos dias, ou a partir de que folha iniciaram as medidas.

Tabela 4. Relação entre os tratamentos na taxa de aparecimento foliar.

\begin{tabular}{llllll}
\hline \multicolumn{6}{c}{ Taxa de aparecimento foliar (TApF - folha.dia ${ }^{-1}$.perfilho ${ }^{-1}$ ) } \\
\hline \multicolumn{7}{l}{ Trat. 1 } & Trat. 2 & Trat. 3 & Trat. 4 & Trat. 5 \\
\hline Silicato de Cálcio & 0,203 a & 0,200 a & 0,191 a & 0,198 a & 0,193 a \\
Silício Orgânico & 0,198 a & 0,202 a & 0,201 a & 0,189 a & 0,196 a \\
\hline
\end{tabular}

Médias seguidas de mesma letra, na mesma linha, não diferem entre si ao nível de $1 \%$ de significância pelo teste Tukey. Fonte: Elaboração dos autores. 
Resultados superiores em relação ao intervalo de aparecimento foliar e consequentemente inferiores de taxa de aparecimento foliar são encontrados na literatura.

A taxa de aparecimento foliar é considerada a última a ser penalizada sob condições de stress, pois é uma variável morfogênica que mede a dinâmica do fluxo de tecido de plantas, influenciando diretamente cada um dos componentes da estrutura do relvado (tamanho da folha, densidade de perfilhos e folhas verdes/ perfilho). O efeito de limitações nutricionais sobre a taxa de aparecimento foliar não está bem esclarecido, provavelmente por ser esta característica a última que a planta penaliza, ou seja, para manter o desenvolvimento do perfilho, em condições que limitem a disponibilidade do carbono, seria mais lógico que a economia de assimilados começasse pela redução do perfilhamento, passando pela redução no tamanho e na duração de vida da folha.

\section{Alongamento e tamanho final do colmo}

Não foram observadas diferenças estatísticas significativas $(p<0,05)$ entre os tratamentos com silício na taxa de alongamento de colmo (Tabela 5).

Tabela 5: Relação entre os tratamentos na taxa de alongamento de colmo.

\begin{tabular}{cccccc}
\hline \multicolumn{5}{c}{ Taxa de Alongamento de Colmo(cm/dia) } & \\
& Trat. 1 & Trat. 2 & Trat. 3 & Trat. 4 & Trat. 5 \\
\hline Silício Orgânico & 0,642 a & 0,627 a & 0,595 a & 0,537 a & 0,582 a \\
Silicato de Cálcio & 0,615 a & $0,634 \mathrm{a}$ & 0,623 a & 0,624 a & 0,646 a \\
\hline
\end{tabular}

Médias seguidas de mesma letra, não diferem entre si ao nível de $1 \%$ de significância pelo teste Tukey. Fonte: Elaboração dos autores.

Também não foram observadas diferenças estatísticas significativas para o tamanho final de colmo, onde apresentou uma média de 20,50 cm para o silicato de cálcio e 19,39 para o silício orgânico.

\section{4 | CONCLUSÃo}

Diante dos resultados obtidos no presente experimento, considerando a idade da planta, pôde-se concluir que:

- As fontes de silício foram significativas para o tamanho final das folhas.

- As doses de silício, independente da fonte, não influenciaram as medidas morfológicas de crescimento da Brachiaria brizantha cv. Marandu.

Sugerem-se novas pesquisas em relação às investigações morfológicas da cv. Marandu com fontes e doses de silício, porém considerando o envelhecimento e o fator de rebrota para que a planta manifeste seu ciclo de desenvolvimento, para com isso obter dados mais próximos da realidade de um sistema de cultivo.

\section{Referências bibliográficas}

ALEXANDRINO, E. et al.. Características morfogênicas e estruturais na rebrotação da Brachiaria brizantha cv. marandu submetida a três doses de nitrogênio, Revista Brasileira de Zootecnia, Viçosa - MG, v. 33, n. 6, nov.-dez. 2004.

AGARIE, S. et al. Effects of silicon on transpiration and leaf conductance in rice plants (Oryza sativa L.). Plant Production Science, Tokyo, v. 1, p. 89-95, 1998.

ALTOÉ, J; SANTOS, P. M.; TASSIM, T. A. Caracterização morfológica de acessos de Brachiaria brizantha durante fase inicial de desevolvimento. In: CONGRESSO DE INICIAÇÃO CIENTÍFICA, 16, 2008, São Carlos. Anais...São Carlos: UFSCar, 2008, v. 4, p. 401.

CARVALHO, S. P. Efeito do silício na introdução de resistência do sorgo ao pulgãoverde Schizaphis graminium (Rondani, 1852) (Homoptera: Aphididae), 1998, 43 f., Dissertação (Mestrado em Agronomia). Universidade Federal de Lavras. Lavras. 1998. 
DEREN, C. Plant genotypes, silicon concentration and silicon related responses. In: DATNOFF L. E., SNYDER G. H., KORNDÓRFER G. $\mathrm{H}$. (Eds.) Silicon in Agriculture. Amsterdam: Elsevier Science, 2001. Cap. 8, p. 149-158.

DOURADO, R. L. et al.. Respostas morfogênicas da Brachiaria brizantha cv. Piatã submetida a doses de nitrogênio. In: ZOOTEC, XIX, 2009, Águas de Lindóia, SP. Anais... Águas de Lindóia, SP: FZEA/USP-ABZ, 2009, p. 1-4.

EPSTEIN, E. The anomaly of silicon in plant biology. Proceedings of the National Academy of Sciences USA, v. 91, p. 11-17, 1994.

GOMIDE, J. A. Morfogênese e análise de crescimento de gramíneas tropicais. In: SIMPÓSIO INTERNACIONAL SOBRE PRODUÇÃO ANIMAL EM PASTEJO, 1997, Viçosa, MG. Anais... Viçosa, MG: Universidade Federal de Viçosa, 1997, p. 411-430.

LEMAIRE, G.; CHAPMAN, D. Tissue flows in grazed plant communities. In: HODGSON J., ILLIUS A.W. (Eds). The ecology and management of grazing systems. Oxon: $C A B$ International, 1996. p. 3-36.

MENZIES, J. G. et al.. Plant-related silicon research in Canada. In: DATNOFF L. E., SNYDER G. H., KORNDÓRFER G. H. (Eds.) Silicon in Agriculture. Amsterdam: Elsevier Science, 2001. Cap. 20. p. 323-341.

NASCIMENTO JÚNIOR D.; ADESE, B. Acúmulo de biomassa na pastagem. In: SIMPÓSIO SOBRE MANEJO ESTRATÉGICO DA PASTAGEM, 2, 2004, Viçosa. Anais... Viçosa: UFV, 2004. p. 289-330.

RAIJ, B. van. Fertilidade do solo e adubação. Piracicaba: Ceres, Potafos, 1991. 343 p.

SANCHES, A. B. Efeitos do Silicato de cálcio nos atributos químicos do solo e planta, produção e qualidade em capim - Braquiarão [Brachiaria brizantha (hoechst ex A. Rich.) Stapf. cv. MARANDU sob intensidades de pastejo. 2003. Dissertação (Mestrado). Faculdade de Zootecnia e Engenharia de Alimentos da USP, Pirassununga. SILVEIRA, M. C. T. Caracterização morfogênica de oito cultivares do gênero brachiaria e dois do gênero panicum. 2006. Dissertação (Mestrado). Universidade Federal de Viçosa, Viçosa-MG.

TASSIM, T. A. et al... Tolerância ao défice hídrico em acessos de Brachiaria brizantha: taxa de alongamento foliar. In: CONGRESSO DE INICIAÇÃO CIENTÍFICA, 17, 2009, São Carlos. Anais... São Carlos: UFSCar, 2009, v. 5, p. 1126. 
